${ }^{2}$ NOAA/National Severe Storms Laboratory, Norman, OK, USA

${ }^{3}$ Cooperative Institute for Mesoscale Meteorological Studies, University of Oklahoma, Norman, OK, USA

\title{
Tornado outbreaks associated with landfalling hurricanes in the north Atlantic Basin: 1954-2004
}

\author{
S. M. Verbout ${ }^{1}$, D. M. Schultz ${ }^{2,3}$, L. M. Leslie ${ }^{1}$, H. E. Brooks ${ }^{2}$, \\ D. J. Karoly ${ }^{1}$, and K. L. Elmore ${ }^{2,3}$
}

With 10 Figures

Received June 10, 2006; revised July 24, 2006; accepted August 22, 2006

Published online: March 14, 2007 (C) Springer-Verlag 2007

\begin{abstract}
Summary
Tornadoes are a notable potential hazard associated with landfalling hurricanes. The purpose of this paper is to discriminate hurricanes that produce numerous tornadoes (tornado outbreaks) from those that do not (nonoutbreaks). The data consists of all hurricane landfalls that affected the United States from the North Atlantic basin from 1954 to 2004 and the United States tornado record over the same period. Because of the more than twofold increase in the number of reported tornadoes over these 51 years, a simple least-squares linear regression ("the expected number of tornadoes") was fit to the annual number of tornado reports to represent a baseline for comparison.

The hurricanes were sorted into three categories. The first category, outbreak hurricanes, was determined by hurricanes associated with the number of tornado reports exceeding a threshold of $1.5 \%$ of the annual expected number of tornadoes and at least $8 \mathrm{~F} 1$ and greater tornadoes during the time of landfall (from outer rainbands reaching shore to dissipation of the system). Eighteen hurricane landfalls were classified as outbreak hurricanes. Second, 37 hurricanes having less than $0.5 \%$ of the annual expected number of tornadoes were classified as nonoutbreak landfalls. Finally, 28 hurricanes that were neither outbreak nor nonoutbreak hurricanes were classified as midclass hurricane landfalls.

Stronger hurricanes are more likely to produce tornado outbreaks than weaker hurricanes. While $78 \%$ of outbreak hurricanes were category 2 or greater at landfall, only $32 \%$ of nonoutbreak hurricanes were category 2 or greater at landfall. Hurricanes that made landfall along the southern coast
\end{abstract}

of the United States and recurved northeastward were more likely to produce tornadoes than those that made landfall along the east coast or those that made landfall along the southern coast but did not recurve. Recurvature was associated with a $500-\mathrm{hPa}$ trough in the jet stream, which also contributed to increased deep-layer shear through the hurricane, favoring mesocyclogenesis, and increased the low-level shear, favoring tornadogenesis. The origin of the hurricane, date of landfall, and El Niño-Southern Oscillation phase do not appear to be factors in outbreak hurricane creation. The results of this study help clarify inconsistencies in the previous literature regarding tornado occurrences in landfalling hurricanes.

\section{Introduction}

Wind damage, storm surges, and inland flooding are hazards faced by coastal communities in the southern and eastern United States due to landfalling hurricanes. Neumann et al (1999) found that the United States Atlantic and Gulf coasts experience an average of 1.7 landfalling, or nearlandfalling, hurricanes per year. Hurricane-related property losses accounted for nearly $40 \%$ of all insured losses in the United States from 1984 to 1993, exceeding earthquake losses by a factor of four (Pielke and Pielke, 1997). 
A hurricane with watches or warnings in effect is considered a land-threatening hurricane (Franklin et al, 2003). Tornadoes are a notable potential hazard associated with land-threatening hurricanes. Ten percent of hurricane-related fatalities from 1948 to 1972 were attributed to tornadoes near or during the time of landfall (Novlan and Gray, 1974). Hurricane Allen's (1980) landfall in Texas produced well over $\$ 70$ million in damage associated with hurricane-spawned tornadoes alone (Gentry, 1983). Other examples of tornadoes associated with tropical systems are described in Gray (1919), Hills (1929), Tannehill (1938, pp 24-25), Malkin and Galway (1953), Sadowski (1962), Rudd (1964), Pearson and Sadowski (1965), Orton (1970), Hoadley (1981), Stiegler and Fujita (1982), McCaul (1987), Grazulis (1993, pp 124-127), McCaul et al (2004), and Watson et al (2005).

Emergency managers typically treat landfalling hurricanes differently than tornadoes. When a hurricane threatens landfall, coastal communities are evacuated inland to large buildings with free-spanning roofs that can house many people, such as school gymnasiums and armories. On the other hand, these types of buildings are more susceptible to collapse in a tornado. This quandary proves problematic for organizations such as the Red Cross and the Federal Emergency Management Agency, who work to shelter those evacuated from coastal regions.

Most tornadoes generated by hurricanes occur within $24 \mathrm{~h}$ of landfall (e.g., Hill et al, 1966; Novlan and Gray, 1974; Gentry, 1983; McCaul,
1991). Although some tornadoes can occur within the inner rainbands or in the eyewall ("core" tornadoes; Gentry, 1983; Weiss, 1987; McCaul, 1991), most tornadoes form in the outer rainbands where convection can be strong (e.g., Hill et al, 1966; Novlan and Gray, 1974). For example, Weiss (1987) found that $74 \%$ of postlandfall tornadoes from 1964 to 1983 were generated by outer-rainband convection.

Tornadoes spawned by hurricanes can have different characteristics than tornadoes spawned by midlatitude supercells or squall lines. For instance, the parent mesocyclones in hurricanes tend to have shallower circulations than those associated with midlatitude supercells in the central United States (average depth of 3-3.5 km vs $6 \mathrm{~km}$, respectively) (McCaul, 1987; 1991; McCaul and Weisman, 1996; Spratt et al, 1997; McCaul et al, 2004). McCaul and Weisman (1996) argued that the lack of strong surface cold pools (a source of horizontal vorticity) associated with supercells in the moist tropical environment may limit the production of strong tornadoes by tilting. Traditional tornadic radar signatures (e.g., bounded weak echo regions, hook echoes, and appendages) may be subtle, or even nonexistent for hurricane-spawned tornadoes (Spratt et al, 1997). In addition, some of the tornado-producing supercells during Tropical Storm Beryl (1994) did not contain any cloud-to-ground lightning (McCaul et al, 2004). Finally, hurricanerelated tornadoes tend to be weaker, and have half the path width and path length as tornadoes formed by other systems (Smith, 1965).

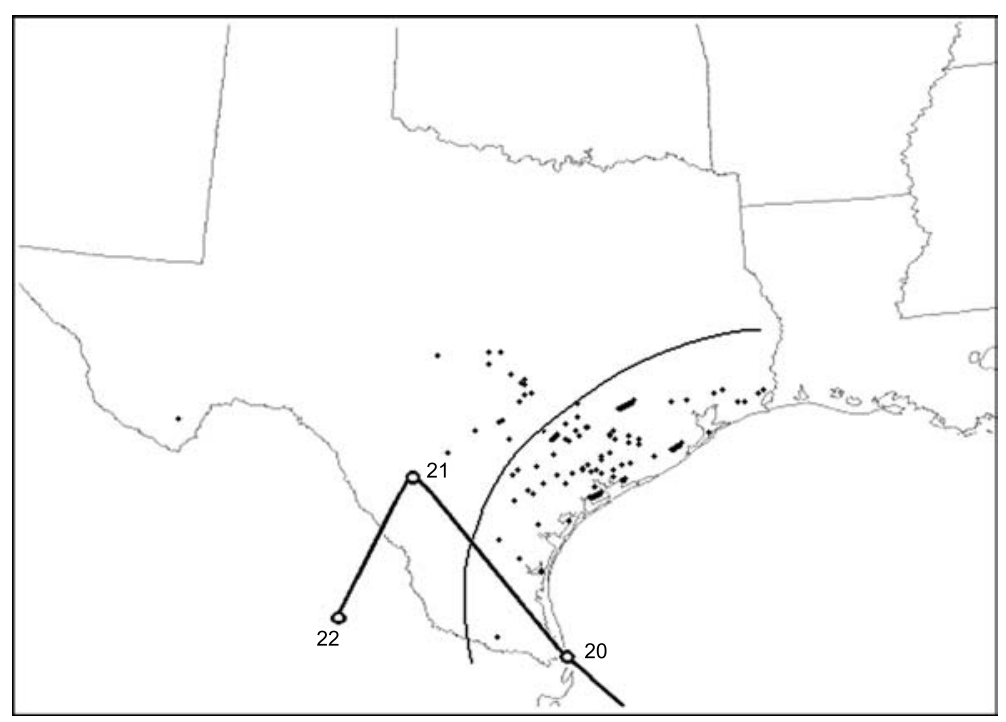

Fig. 1. Track of hurricane Beulah (1967) from 20-22 September. Hollow circles indicate center of circulation at 0000 UTC on each day. Thin line denotes a distance of $100 \mathrm{~nm}$ from shore. Individual tornado reports are marked with small plus signs 
McCaul (1991) examined the number of tornadoes and thermodynamic properties associated with all tropical cyclones (defined as all hurricanes, tropical storms, tropical depressions, and subtropical storms) from 1948 to 1986, grouping tornado outbreaks into three classifications: minor (not more than 8 tornadoes), major (more than 8 tornadoes), and severe (more than 24 tornadoes). He found that 413 of the 626 total tornadoes $(66 \%)$ were produced by 18 major tornado outbreaks, of which four were severe.

One of the most prominent tornadic hurricanes was Hurricane Beulah (1967) (Orton, 1970). Beulah made landfall near Brownsville, Texas, and produced 117 tornadoes in the southern portion of the state (Fig. 1). The majority of tornadoes occurred on 20 September when 67 tornadoes were reported with Beulah's landfall (Orton, 1970). Of those 67 tornadoes, 21 were rated F1 and greater on the Fujita scale. Almost 40 years passed since any hurricane produced nearly 100 tornadoes at landfall. Data from the Storm Prediction Center (SPC) showed that hurricane Frances (2004) produced 99 tornadoes and Hurricane Ivan (2004) produced 117 tornadoes (e.g., Watson et al, 2005). The large number of tornadoes associated with Beulah (1967), Frances (2004), and Ivan (2004) clearly demonstrates the need to examine and characterize these types of events for future hurricane preparedness.

The purpose of this paper is to examine the differences between outbreak and nonoutbreak hurricane landfalls. Section 2 describes the dataset used in this study. Section 3 discusses our criteria for identifying days with many tornadoes, as determined by the method in Verbout et al (2005). Section 4 outlines the three types of hurricanes identified by this study. Characteristics such as intensity of the hurricane, landfall location, synoptic pattern, hurricane origin, date of landfall, and El Niño-Southern Oscillation (ENSO) phase are analyzed in Sect. 5. Lastly, Sect. 6 summarizes the conditions favoring tornado outbreaks associated with landfalling hurricanes.

\section{Data}

A main concern surrounding any tornadic event is the accuracy and availability of reports (e.g., Pearson, 1975; Doswell and Burgess, 1988;
Grazulis, 1993, pp 187-195; Hagemeyer, 1998; Hagemeyer and Spratt, 2002). This problem is amplified because hurricane-force winds, heavy rains, and storm surge can obscure tornado verification. The present study inspected all tornado reports from the United States tornado database (McCarthy, 2003) from 1954 to 2004 two days prior and four days following the landfall of a hurricane, similar to the criteria chosen in Weiss (1987) and fig. 15 in McCaul (1991). Because Weiss (1985) found $85 \%$ of tornadoes associated with tropical systems were attributed to hurricane-strength storms, we chose to focus strictly on hurricanes (category 1 or greater on the SaffirSimpson scale). All landfalling hurricanes that affected the United States originating from the North Atlantic basin from 1954 to 2004 were identified from the National Hurricane Center/ Tropical Prediction Center (NHC/TPC) archives. These hurricanes included not only those that made landfall in the United States, but also those that made landfall in northeastern Mexico and produced tornadoes in the United States. Tornadoes were considered related to the hurricane if the tornado report occurred within $400 \mathrm{~km}$ of the cyclone center. This distance is consistent with Spratt et al's (1997) definition of maximum range. This definition may need to be expanded for future investigations to account for Hurricane Katrina (2005) because of the extremely large, unparalleled size of Katrina's outer rainbands. At the time of this study, the 2005 hurricane season was ongoing and official hurricane and tornado data had not been verified.

\section{Defining a big tornado day}

As stated earlier, the large number of tornadoes associated with hurricanes Beulah (1967), Frances (2004), and Ivan (2004) clearly demonstrates the need to examine these types of events for future hurricane preparedness. With the aim of studying tornado outbreaks associated with landfalling hurricanes, we first examined the daily United States tornado record from 1954 to 2004 . Verbout et al (2005) defined a "big tornado day" as a single day where numerous tornadoes and/or many tornadoes exceeding a specified intensity threshold were reported. This term was chosen with the intention of distinguishing a big tornado day from previous applications of the word out- 


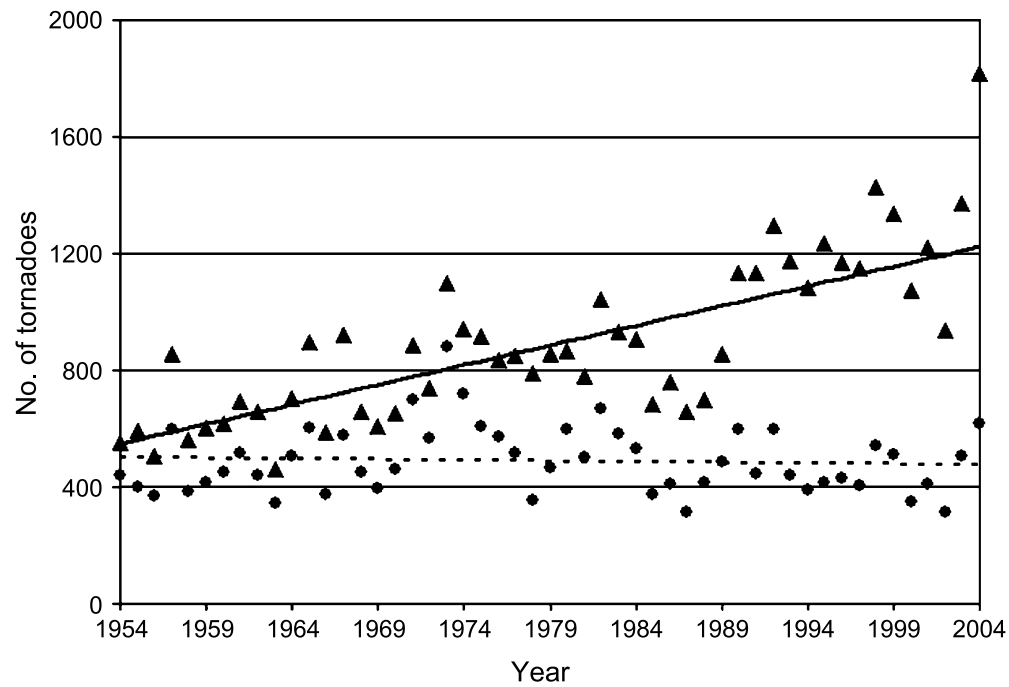

Fig. 2. Annual number of reported tornadoes (triangles) and annual number of F1 and greater reported tornadoes (circles) from 1954 to 2004. Black line and dashed line indicate linear regression fit to each series break. Overall, the total number of tornadoes in the United States tornado database (McCarthy, 2003) had doubled from roughly 600 per year in the 1950 s to around 1200 per year in the 2000s (Fig. 2). A least-squares linear regression was fit to the annual number of reported tornadoes over the period 1954-2004 in order to adjust for the general increase in reports (Verbout et al, 2005). Such a procedure allows comparison of the tornado record through the decades.
Traditionally, the number of F2 and greater tornadoes has been used to determine the significance of a tornado event. However, Verbout et al (2005) demonstrated that over this time period, the F2 and greater series had some overrating problems early in the dataset. Therefore, the F1 and greater time series is more stationary over this period in comparison with the $F 2$ and greater series. Thus, a big tornado day is determined by a fraction of the annual expected

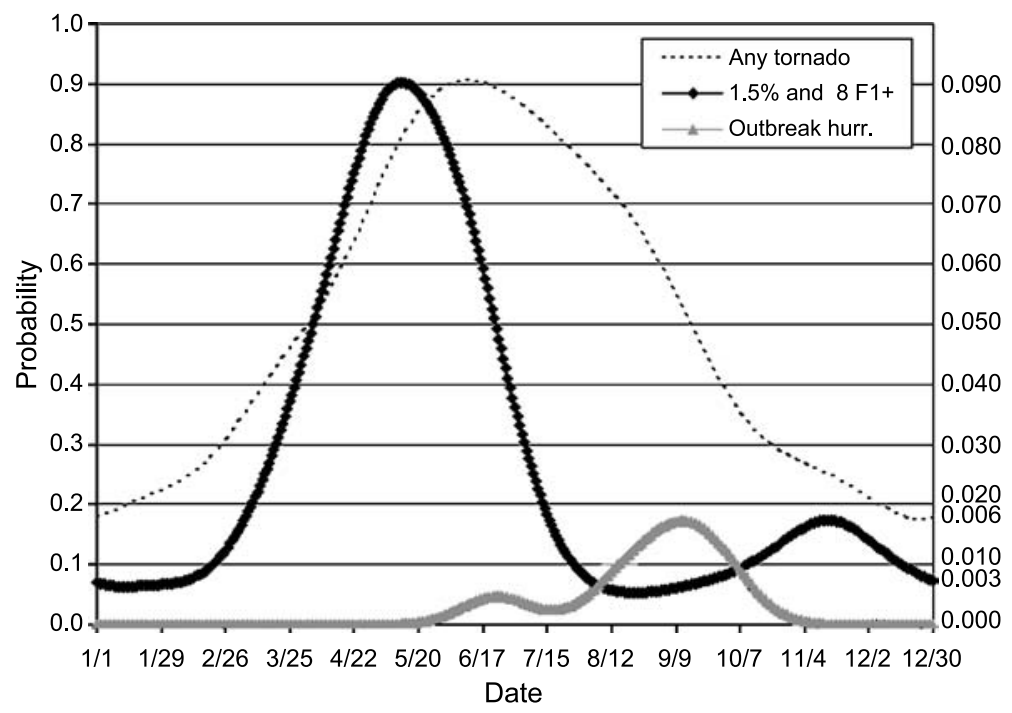

Fig. 3. Dashed line (scale on left side of graph) is the probability of having any tornado reported somewhere in the United States by day of year, based on the 1980-1999 record (Brooks et al, 2003). Solid black line (black scale on right side of graph) displays the probability of a single day having at least $1.5 \%$ of the expected annual value and at least $8 \mathrm{~F} 1$ and greater tornadoes reported, based on the 1954-2004 record. Solid gray line (gray scale on right side of graph) displays the probability distribution of all outbreak hurricane cases from 1954-2004. Solid black curve is scaled by a factor of 9 and solid gray curve is scaled by a factor of 30. Curves were generated using kernel density estimation with a Gaussian smoother with $\sigma_{t}=15$ days (Brooks et al, 2003) 
number of tornadoes associated with the linear regression and/or a minimum number of $\mathrm{F} 1$ and greater tornado reports (Verbout et al, 2005).

In order to assess the daily probability of tornado occurrence in the United States, Verbout et al (2005) constructed a statistical model of the daily mean number of tornadoes reported from 1954 to 2004 using a kernel density estimation technique with a Gaussian smoother $\left(\sigma_{t}=15\right.$ days) (Brooks et al, 2003). This technique was used to smooth the data in time and space and estimate the probability of any tornado occurring anywhere in the United States on any given day (Fig. 3; dashed line). The peak probability of $90 \%$ chance of any tornado occurring in the United States is near June 12 (Brooks et al, 2003). However, once the data is constrained by thresholds with the purpose of determining a big tornado day (for example, $1.5 \%$ of the linear regression value and at least $8 \mathrm{~F} 1$ and greater tornadoes), the probability distribution changes. The black curve in Fig. 3 illustrates the probability of these days from 1954-2004 and shows that the largest peak occurs in mid-May, nearly three weeks earlier in the year than the any-tornado curve. Hence, big tornado days are more likely to occur slightly earlier in the year than just any day with a tornado. (See sect. 3e in Verbout et al (2005) for further discussion of this point.)

Tornadoes embedded within hurricanes can occur within a one-day period (e.g., hurricane Edith, 1971) to over a three-day period (e.g., hurricane Frances, 2004). Because a landfalling hurricane can spawn tornadoes over several days, this paper considers the number of tornadoes over the duration of landfall (from outer rainbands reaching shore to dissipation of the system) as a natural temporal limit.

\section{Hurricane classifications}

In order to determine if an outbreak hurricane occurred, thresholds must again applied to the tornado data. As again discussed in Verbout et al (2005), thresholds must be chosen arbitrarily depending on the number of events one wishes to analyze. For this study, a threshold of $1.5 \%$ of the linear regression value and at least $8 \mathrm{~F} 1$ and greater tornadoes was chosen to distinguish between outbreak and nonoutbreak hurricanes in order to create a sizeable outbreak dataset. As a result, a total of 83 hurricane landfalls were classified as outbreak (18 cases), nonoutbreak (37 cases), or midclass (28 cases) hurricanes.

\subsection{Outbreak hurricanes}

Hurricanes with tornado reports exceeding a threshold of $1.5 \%$ of the annual expected number and at least $8 \mathrm{~F} 1$ and greater tornadoes were classified as outbreak hurricanes. For instance, the $1.5 \%$ annual expected value for 1954 was 8; therefore, at least 8 tornadoes were needed for an outbreak (Fig. 4). For 2003, however, the $1.5 \%$ annual expected value was 18 (Fig. 4). These thresholds generated 18 outbreak hurricane landfalls (Table 1). When the 18 outbreak hurricane cases were plotted in Fig. 3 (again using the kernel density estimation technique;

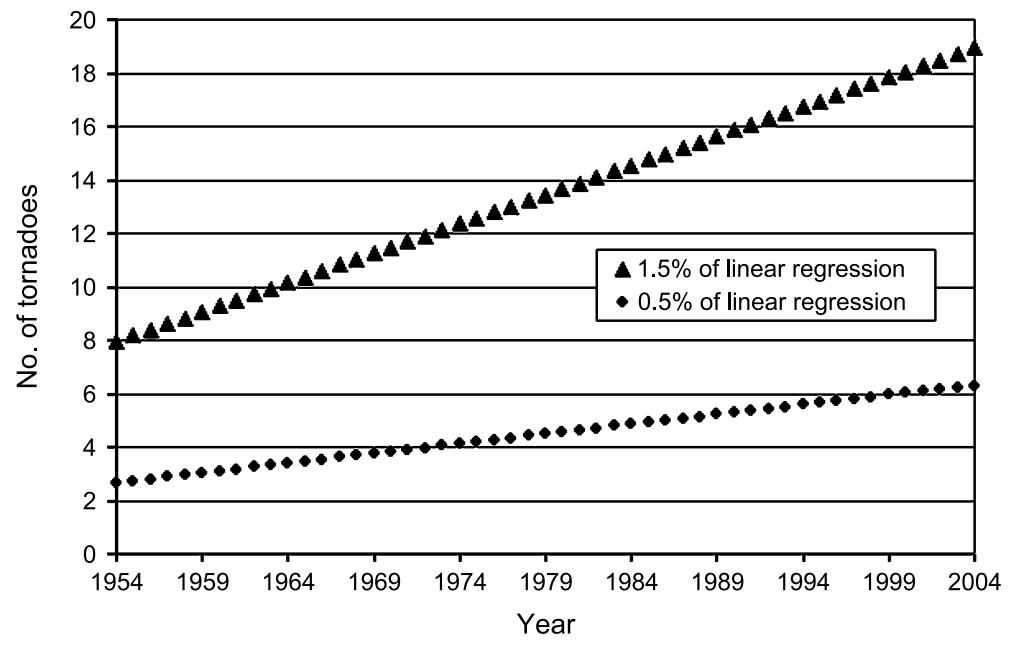

Fig. 4. Graph of the number of tornadoes associated with $1.5 \%$ of the linear regression value (triangles) and $0.5 \%$ of the linear regression value (circles) for each year (1954-2004) 
Table 1. Outbreak cases listed by landfall date. Hurricane name, landfall date, Saffir-Simpson category at time of landfall, total number of reported tornadoes, and number of F1 and greater tornadoes are given

\begin{tabular}{|c|c|c|c|c|}
\hline Name & $\begin{array}{l}\text { Date of } \\
\text { landfall }\end{array}$ & $\begin{array}{l}\text { Cat.@ } \\
\text { landfall }\end{array}$ & $\begin{array}{l}\text { Total } \\
\text { tors }\end{array}$ & $\mathrm{F} 1+$ \\
\hline Audrey\# & $6 / 27 / 1957$ & 4 & 22 & 17 \\
\hline Carla $\#$ & $9 / 11 / 1961$ & 4 & 20 & 19 \\
\hline Cleo & $8 / 27 / 1964$ & 2 & 12 & 9 \\
\hline Hilda & $10 / 4 / 1964$ & 2 & 12 & 10 \\
\hline Beulah\# & $9 / 20 / 1967$ & 4 & 117 & 21 \\
\hline Edith $(\mathrm{LA})^{*}$ & $9 / 16 / 1971$ & 2 & 16 & 15 \\
\hline Agnes $(\mathrm{FL})^{*}$ & $6 / 19 / 1972$ & 1 & 28 & 22 \\
\hline Babe & $9 / 5 / 1977$ & 1 & 14 & 13 \\
\hline David & $9 / 3 / 1979$ & 2 & 34 & 26 \\
\hline Allen $\#$ & $8 / 10 / 1980$ & 3 & 29 & 19 \\
\hline Danny & $8 / 15 / 1985$ & 1 & 42 & 29 \\
\hline Gilbert $\#$ & $9 / 16 / 1988$ & 4 & 41 & 13 \\
\hline Andrew (LA)* & $8 / 26 / 1992$ & 3 & 56 & 23 \\
\hline Opal & $10 / 4 / 1995$ & 1 & 32 & 8 \\
\hline Georges & $9 / 28 / 1998$ & 2 & 46 & 21 \\
\hline Frances & $9 / 5 / 2004$ & 2 & 99 & 36 \\
\hline Ivan & $9 / 16 / 2004$ & 3 & 117 & 68 \\
\hline Jeanne & $9 / 26 / 2004$ & 3 & 40 & 14 \\
\hline
\end{tabular}

\# Texas landfall

* Multiple landfall

gray curve), the peak occurs in early to midSeptember (most active hurricane time in the North Atlantic basin). These results show that the outbreak hurricane tornadoes peak probability (gray curve; $\sim 0.005$ ) comprises nearly all the daily big tornado day signal $(1.5 \%$ and 8 F1+ black curve; $\sim 0.006$ ) for early to midSeptember. Thus, if a big tornado day occurred in early to mid September, chances are it occurred within an outbreak hurricane.

Eleven of the 18 cases defined by McCaul (1991) are included in this study, while seven additional storms since 1986 have been added to this dataset (Gilbert, 1988; Andrew, 1992; Opal, 1995; Georges, 1998; Frances, 2004; Ivan, 2004; Jeanne, 2004). Hurricane Alicia (1983) was not considered an outbreak hurricane in our study because only two of the total 22 reported tornadoes were rated F1 or greater. Similarly, Curtis (2004) created a dataset of 13 outbreak hurricanes from 1960 to 1999 based on 20 or more reported tornadoes (Galway, 1975; 1977). Ten of the 13 cases in Curtis's (2004) dataset appeared in our dataset - the excluded three were hurricane Alicia (1983), described above, and tropical storms Beryl (1994) and Josephine (1996). Beryl
(1994) and Josephine (1996) were omitted from this dataset because of the strict requirement of the storm needing to be of hurricane strength (according to Saffir-Simpson scale) at some point in its lifetime. Additionally, Curtis's (2004) dataset did not include hurricanes Audrey (1957), Cleo (1964), Hilda (1964), and Babe (1977) because of his higher threshold that required at least 20 tornadoes. Finally, 10 of the $13(77 \%)$ outbreaks identified by Curtis (2004) occurred in the last 25 years (1979 to 2004), indicating that the temporal increase in reports (Fig. 2) was perhaps reflected in his dataset.

\subsection{Nonoutbreak hurricanes}

Hurricanes with less than $0.5 \%$ of the annual expected number of tornado reports were classified as nonoutbreak hurricane landfalls (Table 2). For example, no more than three tornadoes could have occurred in 1954, and no more than six in 2004 (Fig. 4). From 1954 to 2004, there were 37 cases of nonoutbreak hurricane landfalls. Several of these cases include hurricanes that made multiple landfalls and either had no reported tornadoes or very few (Table 2). Note that five nonoutbreak cases (Diane, 1955; Ione, 1955; Cindy, 1959; Gloria, 1985; Charley, 1986) narrowly made landfall and quickly turned back out to sea, allowing little time for the hurricane to produce tornadoes over land (Table 2). Most recently, 1999 had three nonoutbreak hurricane landfalls (Bret, Dennis, and Irene). Bret (1999) was the first hurricane to make landfall on the Texas coastline since hurricanes Chantal and Jerry (1989) and the first intense hurricane (category 3 or greater on Saffir-Simpson scale) to hit Texas since hurricane Alicia (1983).

\subsection{Midclass hurricanes}

Many landfalling hurricanes produced several tornadoes but could not be labeled strictly outbreak or nonoutbreak. Those cases that fell between the two thresholds were classified as midclass hurricanes. There were 28 midclass hurricanes identified from 1954 to 2004 (Table 3). A few of these midclass hurricanes failed to make outbreak classification because of too few F1 and greater tornadoes reported. For example, hurricanes Alicia (1983) and Lili (2002) both had the minimum 
Table 2. Same as Table 1, except for nonoutbreak cases

\begin{tabular}{|c|c|c|c|c|}
\hline Name & $\begin{array}{l}\text { Date of } \\
\text { landfall }\end{array}$ & $\begin{array}{l}\text { Cat.@ } \\
\text { landfall }\end{array}$ & $\begin{array}{l}\text { Total } \\
\text { tors }\end{array}$ & $\mathrm{F} 1+$ \\
\hline Alice $\#$ & $6 / 25 / 1954$ & 1 & 0 & 0 \\
\hline Hazel & $10 / 15 / 1954$ & 2 & 0 & 0 \\
\hline Diane $e^{!, \&}$ & $8 / 17 / 1955$ & 1 & 1 & 1 \\
\hline Ione $e^{!, \&}$ & $9 / 19 / 1955$ & 1 & 0 & 0 \\
\hline Cindy $y^{!, \&}$ & $7 / 9 / 1959$ & 1 & 1 & 1 \\
\hline Debra\# & $7 / 25 / 1959$ & 1 & 1 & 0 \\
\hline Donna $(\mathrm{S} . \mathrm{FL})^{*}$ & $9 / 10 / 1960$ & 4 & 0 & 0 \\
\hline Donna $(\mathrm{CT})^{*}$ & $9 / 12 / 1960$ & 1 & 0 & 0 \\
\hline Cindy $\#$ & $9 / 17 / 1963$ & 1 & 0 & 0 \\
\hline Dora & $9 / 10 / 1964$ & 2 & 3 & 2 \\
\hline Isbell $(\mathrm{NC})^{*}$ & $10 / 16 / 1964$ & 0 & 0 & 0 \\
\hline Betsy $(\mathrm{S} . \mathrm{FL})^{*}$ & $9 / 8 / 1965$ & 3 & 2 & 1 \\
\hline Alma & $6 / 9 / 1966$ & 1 & 4 & 2 \\
\hline Gladys & $10 / 19 / 1968$ & 1 & 2 & 2 \\
\hline Camille & $8 / 18 / 1969$ & 5 & 3 & 1 \\
\hline Fern $(\mathrm{LA})^{*}$ & $9 / 4 / 1971$ & 0 & 0 & 0 \\
\hline Fern $(\mathrm{TX})^{*, \#}$ & $9 / 10 / 1971$ & 1 & 3 & 2 \\
\hline Edith $(\mathrm{S} . \mathrm{TX})^{*, \#}$ & $9 / 14 / 1971$ & 0 & 0 & 0 \\
\hline Agnes $(\mathrm{NY})^{*}$ & $6 / 22 / 1972$ & 0 & 0 & 0 \\
\hline Diana ${ }^{\&}$ & $9 / 13 / 1984$ & 1 & 1 & 0 \\
\hline Bob $\left(\right.$ S. FL) ${ }^{*}$ & $7 / 23 / 1985$ & 0 & 2 & 0 \\
\hline Bob $(\mathrm{SC})^{*}$ & $7 / 24 / 1985$ & 1 & 3 & 1 \\
\hline Gloria!,\& & $9 / 27 / 1985$ & 1 & 2 & 1 \\
\hline Kate & $11 / 21 / 1985$ & 2 & 0 & 0 \\
\hline Charley!,\& & $8 / 17 / 1986$ & 1 & 5 & 5 \\
\hline Florence & $9 / 10 / 1988$ & 1 & 4 & 0 \\
\hline Chantal $^{\#}$ & $8 / 1 / 1989$ & 1 & 2 & 1 \\
\hline Hugo \& & $9 / 22 / 1989$ & 4 & 2 & 2 \\
\hline Bob $(\mathrm{MA})^{*}$ & 8/19/1991 & 2 & 3 & 2 \\
\hline Andrew $(\mathrm{FL})^{*}$ & $8 / 24 / 1992$ & 5 & 0 & 0 \\
\hline Fran & $9 / 6 / 1996$ & 3 & 2 & 1 \\
\hline Bret $^{\#}$ & $8 / 23 / 1999$ & 4 & 5 & 0 \\
\hline Dennis & $9 / 5 / 1999$ & 0 & 2 & 1 \\
\hline Irene & $10 / 15 / 1999$ & 1 & 5 & 4 \\
\hline Gordon & $9 / 18 / 2000$ & 0 & 5 & 1 \\
\hline Claudette $\#$ & $7 / 15 / 2003$ & 1 & 0 & 0 \\
\hline Isabel & $9 / 18 / 2003$ & 2 & 0 & 0 \\
\hline
\end{tabular}

\footnotetext{
! Narrowly made landfall

\# Texas landfall

\& East coast recurver

* Multiple landfall
}

number of tornadoes needed (22 and 26, respectively), yet not enough F1 and greater tornadoes were reported ( 2 and 5 , respectively). On the other hand, hurricanes Isbell (1964) and Juan (1985) did have 8 F1 and greater reported tornadoes, but the 9 and 12 total tornadoes (respectively), however, fell short of the $1.5 \%$ criterion (Fig. 4). Another midclass case is hurricane Gracie (1959). Gracie only had six reported tornadoes associated with landfall, but three of the six tornadoes were rated F3.
Table 3. Same as Table 1, except for midclass cases

\begin{tabular}{|c|c|c|c|c|}
\hline Name & $\begin{array}{l}\text { Date of } \\
\text { landfall }\end{array}$ & $\begin{array}{l}\text { Cat. @ } \\
\text { landfall }\end{array}$ & $\begin{array}{l}\text { Total } \\
\text { tors }\end{array}$ & $\mathrm{F} 1+$ \\
\hline Connie & $8 / 12 / 1955$ & 1 & 4 & 4 \\
\hline Flossy & $9 / 24 / 1956$ & 1 & 5 & 4 \\
\hline Gracie & 9/29/1959 & 3 & 6 & 6 \\
\hline Donna $(\mathrm{NC})^{*}$ & $9 / 11 / 1960$ & 2 & 4 & 4 \\
\hline Ethel & $9 / 15 / 1960$ & 1 & 5 & 4 \\
\hline Isbell (S. FL)* & $10 / 14 / 1964$ & 3 & 9 & 8 \\
\hline Betsy $(\mathrm{LA})^{*}$ & $9 / 10 / 1965$ & 2 & 4 & 3 \\
\hline Celia & $8 / 3 / 1970$ & 1 & 8 & 5 \\
\hline Carmen & $9 / 8 / 1974$ & 3 & 5 & 3 \\
\hline Eloise & $9 / 23 / 1975$ & 3 & 5 & 4 \\
\hline Bob & $7 / 11 / 1979$ & 1 & 8 & 5 \\
\hline Frederic & 9/13/1979 & 2 & 10 & 4 \\
\hline Alicia & $9 / 18 / 1983$ & 3 & 22 & 2 \\
\hline Elena & $9 / 2 / 1985$ & 3 & 9 & 6 \\
\hline Juan & $10 / 29 / 1985$ & 1 & 12 & 8 \\
\hline Bonnie & $6 / 26 / 1986$ & 1 & 5 & 5 \\
\hline Jerry & $10 / 16 / 1989$ & 1 & 7 & 1 \\
\hline Bob $(\mathrm{NC})^{*}$ & 8/18/1991 & 3 & 6 & 4 \\
\hline Gordon & $11 / 16 / 1994$ & 0 & 6 & 3 \\
\hline Allison & $6 / 5 / 1995$ & 0 & 6 & 5 \\
\hline Erin & $8 / 2 / 1995$ & 1 & 12 & 2 \\
\hline Bertha & $7 / 13 / 1996$ & 2 & 14 & 6 \\
\hline Danny & $7 / 18 / 1997$ & 1 & 12 & 6 \\
\hline Bonnie & $8 / 27 / 1998$ & 2 & 8 & 3 \\
\hline Floyd & 9/16/1999 & 2 & 16 & 4 \\
\hline Lili & $10 / 3 / 2002$ & 1 & 26 & 5 \\
\hline Charley (S. FL)* & $8 / 13 / 2004$ & 4 & 12 & 6 \\
\hline Charley $(\mathrm{SC})^{*}$ & $8 / 14 / 2004$ & 1 & 7 & 1 \\
\hline
\end{tabular}

* Multiple landfall

\section{Discriminating between outbreak and nonoutbreak hurricanes}

Of the 83 hurricane landfalls in this study (Tables $1-3)$, only 14 (17\%) had no reported tornadoes. Of those 14, only four have occurred since 1973, suggesting that early tornado records, especially for weaker tornadoes, may be incomplete (e.g., Smith, 1965; Hill et al, 1966; Gentry, 1983; Hagemeyer, 1998; Verbout et al, 2005). Thus, the threat of tornadoes faces forecasters with nearly every hurricane. What determines the conditions for especially prolific tornado-producing hurricanes when tornado watches may be required? In this section, we examine various characteristics that may prove useful in discriminating outbreak cases from nonoutbreak cases. These include the intensity of the hurricane, landfall location, synoptic pattern, hurricane origin, date of landfall, and ENSO phase. 


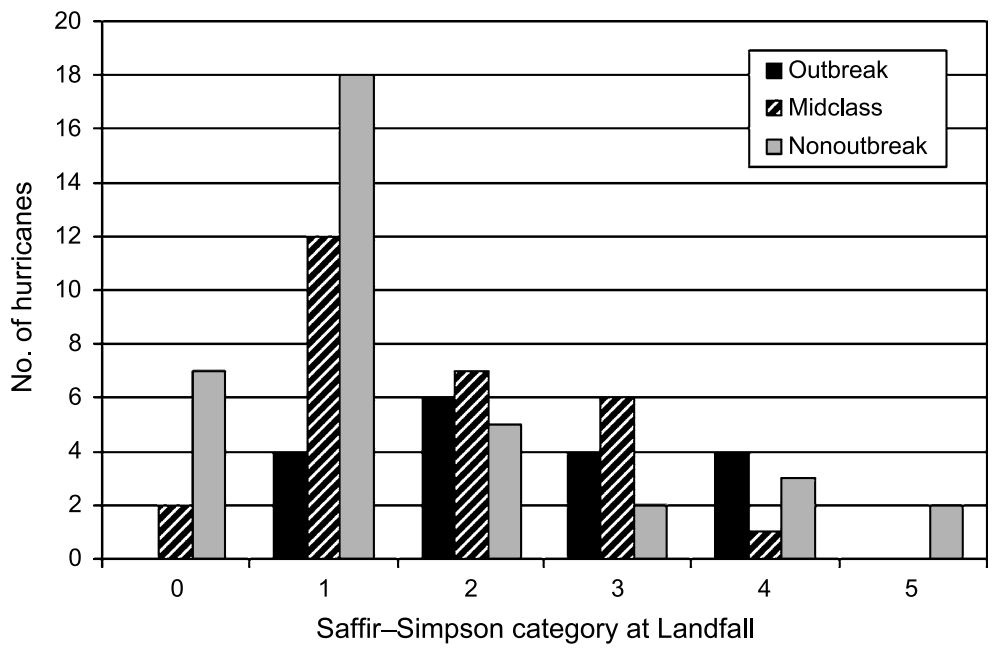

Fig. 5. Number of outbreak (black), midclass (gray hatched), and nonoutbreak (gray) hurricanes listed by Saffir-Simpson category (1-5) at time of landfall. Category 0 represents storms that were not hurricane strength at time of landfall

\subsection{Hurricane intensity}

Previous research has indicated that stronger hurricanes are more likely to produce tornadoes than weaker ones (Hill et al, 1966; Novlan and Gray, 1974; Gentry, 1983; Weiss, 1985; McCaul, 1991). In this study, the Saffir-Simpson scale, a measure of the maximum near-surface wind speed, was used as a measure of hurricane intensity. The Saffir-Simpson scale ranges from 1 to 5 , with 5 having the strongest winds. A category 0 was included in this study to account for sub hurricane-force winds. Most hurricanes are on the low end of the Saffir-Simpson scale. For example, whereas 34 of 83 hurricane landfalls were category 1 strength at landfall, only two hurricanes were category 5 at landfall: hurricane Camille (1969; nonoutbreak case) and hurricane Andrew (Florida 1992 landfall; nonoutbreak case) recently upgraded to a category 5 (Landsea et al, 2004).

Figure 5 shows the distribution of SaffirSimpson category of each classification of hurricane (outbreak, nonoutbreak, or midclass) at landfall. Forty hurricanes were of at least category 2 at landfall and 43 were rated categories 1 or 0 . Thirty-five percent (14 of 40) of all category 2 or greater hurricanes at landfall were associated with outbreaks, whereas $30 \%$ (12 of 40) were associated with nonoutbreaks (Fig. 5). In addition, $78 \%$ (14 of 18) of outbreak hurricanes were category 2 or greater at landfall, and only $32 \%$ (12 of 37) of nonoutbreak hurricanes were category 2 or greater at landfall (Tables 1 and 2). In order to assess the statistical significance of hurricane intensity as a discriminator between outbreak and nonoutbreak cases, a chi-square test was used. In essence, the chi-square test tests associations between two variables and can determine if the association is stronger than random chance alone (i.e., statistically significant; Wilks, 1995, pp 133134). The chi-square test statistic depends on the degrees of freedom. At one degree of freedom, a statistically significant relationship exists between outbreak and nonoutbreak hurricanes and Saffir-Simpson categories 1 and 0 and categories 2 and higher at landfall. A $p$ value equal to 0.002 was found; thus indicating that intensity is a significant parameter at $\alpha=0.01$ level. Clearly, these results show that outbreak hurricanes are more likely to occur if the hurricane is a category 2 or higher at landfall. On the other hand, hurricane intensity at time of landfall is not the only variable that should be considered when assessing the risk of tornado outbreaks embedded within the system.

\subsection{Landfall location}

Previous authors have suggested that hurricane landfalls over the southern United States are more likely to produce tornadoes than those making landfall over the eastern United States (e.g., Hill et al, 1966; Novlan and Gray, 1974; Gentry, 1983; Weiss, 1985; McCaul, 1991). Such a relationship, however, was not apparent from the figures comparing tracks for tornado-producing hurricanes with tracks of non-tornado-producing hurricanes presented by Novlan and Gray (1975). We wished to examine our dataset for such a purported relationship. 


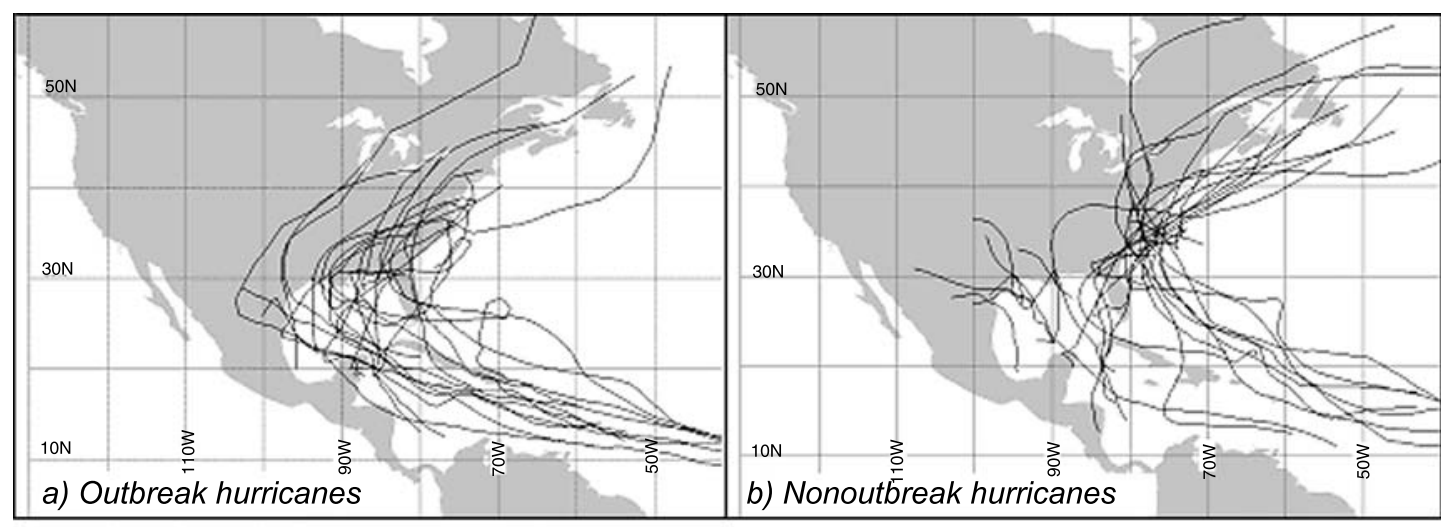

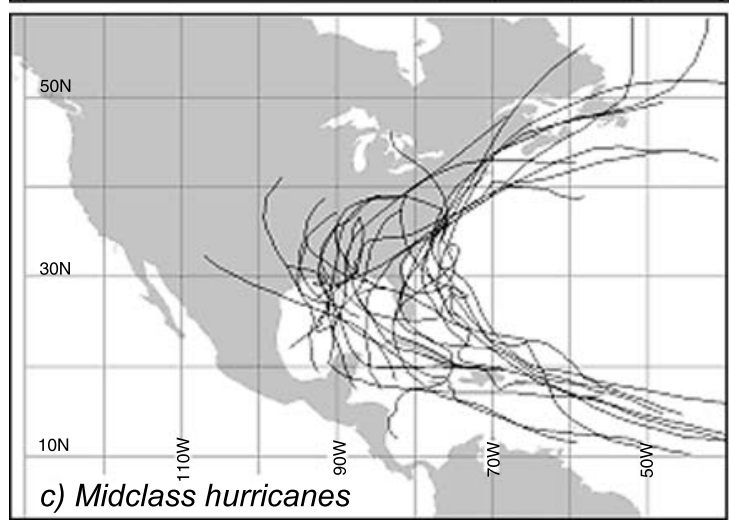

Landfall locations for the 83 hurricanes in our dataset were separated into two categories: southern-coast landfalls (Texas, Louisiana, Mississippi, Alabama, and west coast of Florida) and eastern-coast landfalls (east coast of Florida, Georgia, South and North Carolina, Virginia, and New England states). Overall, 14 of 51 (27\%) landfalls on the southern coast were outbreaks, whereas 4 of $32(13 \%)$ landfalls on the eastern coast were outbreaks. Again, using a chi-square test with one degree of freedom, a statistically significant relationship exists between outbreak and nonoutbreak hurricanes and landfall location at $\alpha=0.10$ level $(p$ value $=0.06)$.

Tracks of the various hurricanes for outbreak, nonoutbreak, and midclass categories were plotted in Fig. 6. When presented in this manner, it is clear that outbreak hurricanes tended to make landfall on the southern coast compared to the eastern coast (Fig. 6a). In addition, nearly all landfalling outbreak hurricanes recurved northeastward after landfall, supporting the results of Smith (1965) and Hill et al (1966). In contrast, nonoutbreak hurricanes tended to fall into one of two categories (Fig. 6b). Although the majority of nonoutbreak hurricanes tended to be those that made landfall on the eastern coasts and recurved northward, there were a lesser group of hurricanes that made landfall over the southern coast, but did not recurve (Fig. 6b). Midclass hurricanes were more evenly divided between southern and east coast landfalls (Fig. 6c). When the distinction is drawn between hurricanes that made landfall on the southern coast that recurved vs hurricanes that made landfall on the southern coast that did not recurve, the statistics produce a different result. In this case, 10 of $21(48 \%)$ hurricanes that made landfall on southern coasts and recurved were outbreaks, whereas 4 of 21 (19\%) hurricanes that made landfall on southern coasts and did not recurve were outbreaks. This presentation suggests that simple rules of thumb such as "landfalling hurricanes on the east coast do not produce tornadoes" can be a serious oversimplification of the actual results.

To understand why recurving hurricanes that made landfall on the southern coast are more likely to produce tornado outbreaks, we need to understand why hurricanes spawn tornadoes. Most tornadoes in hurricanes are spawned in the right-front quadrant of the hurricane relative to the direction of motion of the hurricane (e.g., Malkin and Galway, 1953; Pearson and Sadowski, 1965; Smith, 1965; Orton, 1970; Novlan and Gray, 
1974; Gentry, 1983; McCaul, 1991; Hagemeyer and Hodandish, 1995), the quadrant where the vertical wind shear and helicity tend to be most favorable for tornado production (McCaul, 1991; Bogner et al, 2000). Thus, hurricanes that place their right-front quadrant over land for a longer period of time are more likely to produce greater numbers of tornadoes. Hurricanes approaching southern United States coastlines have more time to interact with land surfaces and have more exposure for the preferred right half of the hurricane to generate tornadoes (Sadowski, 1962; Smith, 1965). Most east coast landfalls, on the other hand, do not penetrate far inland, recurve back over the ocean more quickly, and are less likely to produce a large number of tornadoes (Hill et al, 1966; Gentry, 1983; McCaul, 1991). One notable exception is hurricane Beulah (1967), which produced 117 tornadoes while tracking cyclonically (Fig. 1). Hagemeyer and Hodanish (1995) found that $87 \%$ of tornado-producing hurricanes that made landfall in Florida approached from the west coast of Florida, which placed the right-front quadrant over the state and thus provided more opportunity for the hurricane to produce tornadoes over land (e.g., Hill et al, 1966). As a result, whether storms recurve over land appears to be an important distinction in order to determine whether or not an outbreak may occur. To address the nature of recurving, we look to the next section.

\subsection{Synoptic patterns for landfalling hurricanes that affected Texas}

As mentioned previously, the ability of hurricanes making landfall over the southern United States to produce a tornado outbreak apparently is tied to its ability to recurve northeastward. To explore the reason for this recurvature, we investigate the differences in composite synoptic patterns between outbreaks and nonoutbreaks associated with landfalling hurricanes that affected Texas. We chose to perform this composite on Texas hurricanes for two reasons. First, such hurricanes are relatively abundant in the outbreak and nonoutbreak categories (5 and 8, respectively). Second, these hurricanes reach landfall in a relatively focused geographic region, arriving in a nearly consistent storm track from the southeast (Fig. 6a, b). (Developing such a com- posite analysis for Florida hurricanes was not robust for this reason.) These two criteria allow for the construction of meaningful composite patterns. Composite analyses on the day of landfall were produced using the NOAA-CIRES Climate Diagnostics Center daily-averaged NCEP/ NCAR Reanalysis (Kalnay et al, 1996) web page (http://www.cdc.noaa.gov/composites/ day). Composite analysis using the 6-h data did not produce significantly different results and are not considered here.

Of the five outbreaks that affected Texas, there was one category 3 and four category 4 . In contrast, of the eight nonoutbreaks, all were category 1 hurricanes, except one category 4 and one category 0 . Thus, the synoptic composite might also provide some insight into why the outbreak storms were more intense than the nonoutbreaks.

Although several different composite parameters show differences between outbreaks and nonoutbreaks, we illustrate these differences with $500-\mathrm{hPa}$ geopotential height and surface-850-hPa wind shear parameters (Fig. 7). Composite 500$\mathrm{hPa}$ geopotential height indicates a substantial difference between the Texas outbreaks and nonoutbreaks at landfall (Fig. 7a, b). Whereas the Texas outbreak composite has a 500-hPa trough in the north-central United States, the nonoutbreak composite has a ridge where the jet stream is far poleward of the landfalling hurricanes (Fig. $7 \mathrm{a}, \mathrm{b})$. The anomalies of these composite means (based on 1968-1996 climatology) extend over a large area in the northern United States and southern Canada (Fig. 7c, d). Furthermore, the 500-hPa height anomaly over the landfalling hurricane is over twice as deep, with a gradient of geopotential height (geostrophic wind) twice as great, for the outbreak events (Fig. 7c, d).

Each of the five outbreak events had a trough in the northern United States and each of the eight nonoutbreak events had a ridge in the northern United States (not shown), supporting the composites. However, there remain two questions: (1) is the difference between the means at each grid point significant (local significance), and (2) does the collection of grid points with mean differences have field significance? Elmore et al (2005) presented a nonparametric approach to this problem. Unlike the data considered in Elmore et al (2005), however, serial correlation does not need to be considered in our data. Thus, 


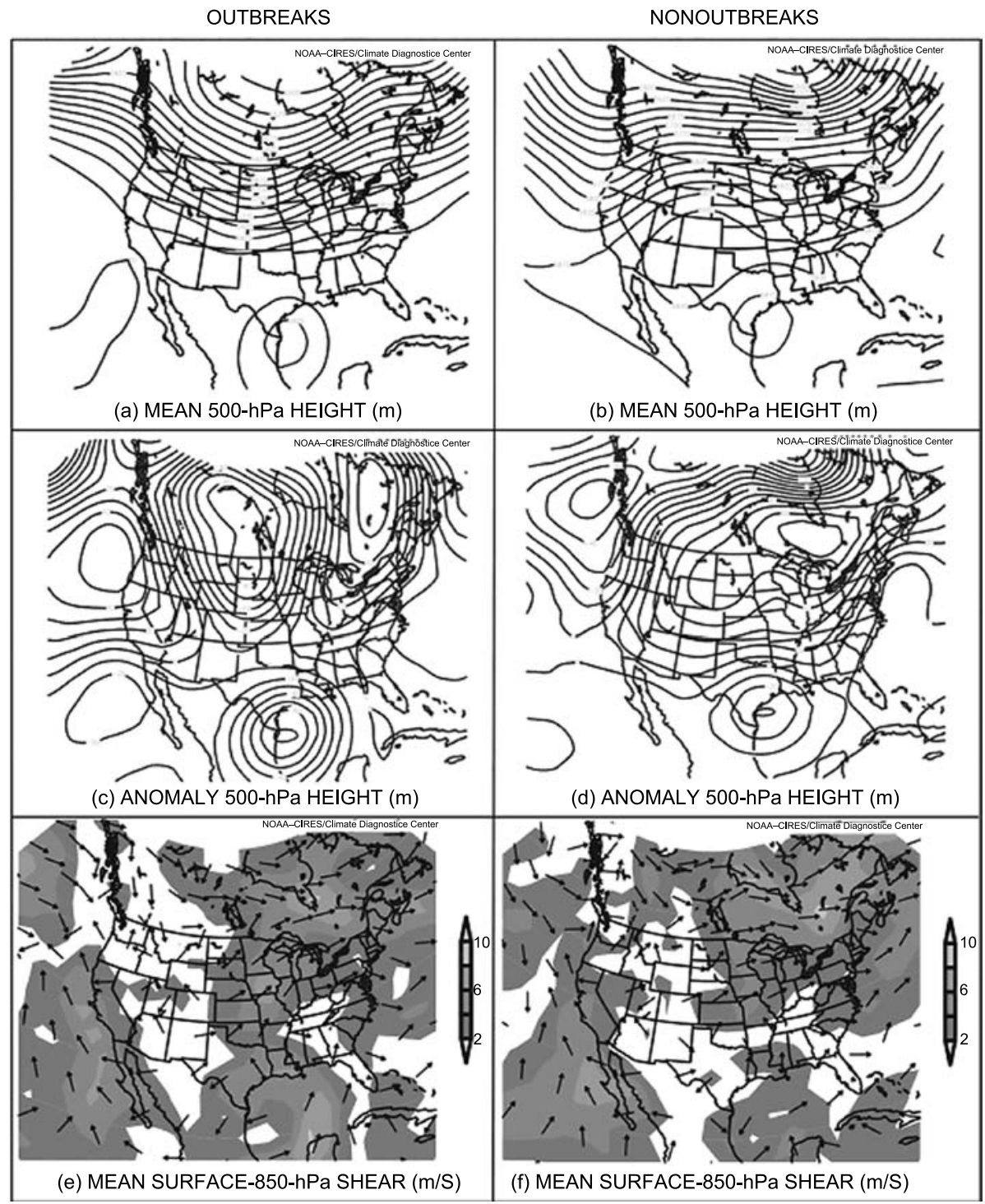

Fig. 7. Composite fields for landfalling hurricanes that affected Texas with tornado outbreaks (left) and nonoutbreaks (right) (Tables 1 and 2). (a) and (b) Mean 500-hPa geopotential height (every $25 \mathrm{~m}) ;(\mathbf{c})$ and (d) anomaly 500-hPa geopotential height from 1968-1996 climatology (every $10 \mathrm{~m}$ ); and (e) and (f) mean surface-850-hPa wind-shear magnitude (shaded every $2 \mathrm{~m} \mathrm{~s}^{-1}$ ) and direction (vectors). Composite maps were provided by the NOAA-CIRES Climate Diagnostics Center, Boulder, Colorado (http://www. cdc.noaa.gov) a permutation test (Efron and Tibshirani, 1993; Elmore et al, 2002) is more accurate than a bootstrap test of the difference between the means. The permutation test is performed at each grid point using 10,000 replicates. All grid points for which the difference between the means is significant at the $\alpha_{\mathrm{p}}=0.05$ level are counted and divided by the total number of grid points, which yields the proportion of the grid containing significant differences. Following Elmore et al (2005), spatial correlation is accommodated using a Monte Carlo process first described in Livezey and Chen (1983), and dubbed the B method by Wang and Shen (1999). The B method for this work uses 10,000 trials and is performed by combining the two fields (5 outbreaks and 8 nonoutbreaks) into a single data matrix with 925 rows and 13 columns. Hence, 13 values are associated with each grid point. The correlation between a uniform random variate at each grid point, as described in Elmore et al (2005), is tested for significance at $\alpha_{\mathrm{f}}=0.05$. The proportion of grid points for which a significant correlation occurs purely by chance yields the minimum proportion of grid points that must possess significant difference between the means for field significance at $\alpha_{\mathrm{p}}=0.05$. For the height data, $14.38 \%$ of the gridpoints display statistically significant mean differences, and $12.97 \%$ are needed for field significance. Thus, the difference between these two fields is significant at the $\alpha_{\mathrm{f}}=0.05$ level.

These results suggest that landfalling hurricanes that affected Texas require greater deep- 
layer (surface-500-hPa) shear over the right-front quadrant in order to spawn a large number of tornadoes, as noted by Wills (1969). This greater deep-layer shear is due to several factors. First, the greater geostrophic wind anomaly at $500-\mathrm{hPa}$ for the outbreak composite (Fig. 7c) suggests that greater deep-layer shear is present compared with the nonoutbreak events (Fig. 7d). Second, the jet stream dipping equatorward over the central United States toward Texas (Fig. 7a) suggests that some interaction between the trough and the hurricane may be helping to produce more intense hurricanes at landfall. As reviewed in Jones et al (2003, their Sect. 3d), a moderate amount of shear associated with midlatitude troughs in the westerlies is sometimes believed to be responsible for hurricane intensification. For nonoutbreak hurricanes, the jet is much farther poleward, effectively isolating the landfalling storm underneath a large-scale $500-\mathrm{hPa}$ ridge (Fig. $7 \mathrm{~b}$ ) in much weaker deep-layer shear. Finally, the differences in the 500-hPa flow over the southeastern United States result in greater deep-layer shear in the outbreak cases than the nonoutbreak cases. The results from these composites support previous research showing that the presence of large deep-layer shear is important for the generation of midlevel mesocyclones in supercell thunderstorms (e.g., McCaul and Weisman, 1996; McCaul et al, 2004), which can spawn tornadoes in the hurricane environment.

Wills (1969), Novlan and Gray (1974), and McCaul (1991) also found that high low-level wind shear was present in tornado-producing hurricanes. The surface-850-hPa (hereafter, lowlevel) wind shear also shows considerable differences between the outbreak and nonoutbreak composites (Fig. 7e, f). The mean low-level wind shear is $4-8 \mathrm{~m} \mathrm{~s}^{-1}$ in an onshore direction northeast of the landfall location for the outbreak events (Fig. 7e), but is about half as strong (2-4 $\mathrm{m} \mathrm{s}^{-1}$ ) for the nonoutbreak events (Fig. 7f). To test the statistical significance of this data, only $4.0 \%$ of the data display significantly different shear values, yet as many as $7.4 \%$ could display a significant difference by chance alone. Hence, the difference between the surface-850-hPa shear for the outbreak and nonoutbreak cases does not possess field significance. If we increase $\alpha_{\mathrm{p}}$ to 0.10 from 0.05 , then field significance is obtained with $\alpha_{\mathrm{f}}=0.05$.
EAST COAST RECURVING NONOUTBREAKS

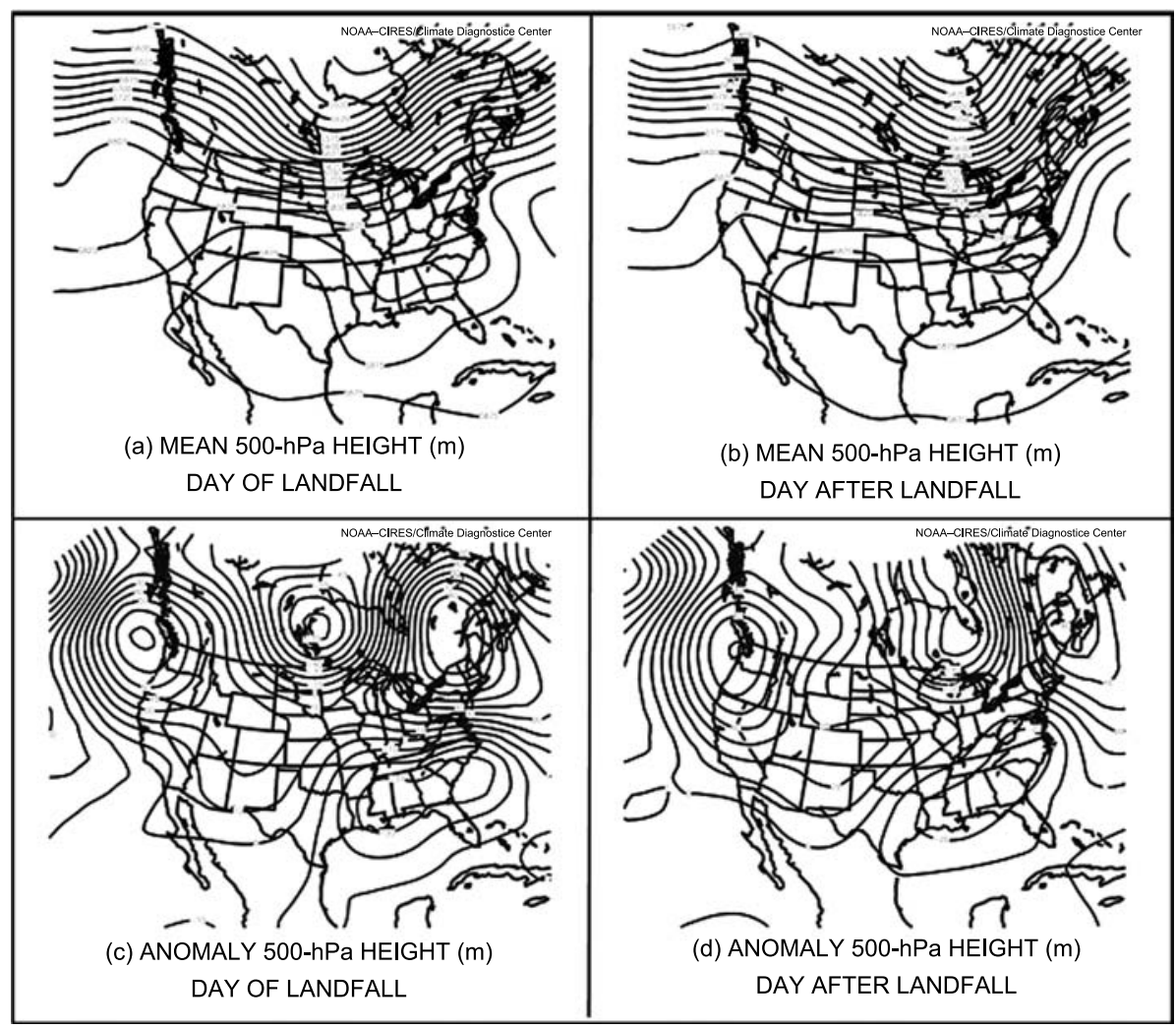

Fig. 8. Composite fields for east coast landfalling hurricanes associated with nonoutbreaks for (a) and (c) day of landfall and (b) and (d) day after landfall (Table 2). (a) and (b) Mean $500-\mathrm{hPa}$ geopotential height (every $25 \mathrm{~m}$ ); (c) and (d) anomaly 500-hPa geopotential height from 1968-1996 climatology (every $10 \mathrm{~m})$. Composite maps were provided by the NOAA-CIRES Climate Diagnostics Center, Boulder, Colorado (http://www. cdc.noaa.gov) 
Thus, the synoptic composites bring some insight into the potential causes for the outbreaks: greater deep-layer shear and greater low-level shear, both associated with more intense hurricanes, favors mesocyclogenesis and tornadogenesis, respectively. What causes the recurvature? The composite of outbreak hurricanes that affected Texas suggests that a trough in the jet stream (Fig. 7a) may transport them northeastward, whereas the nonoutbreaks remain isolated from the jet (Fig. 7b). To test this hypothesis on a different set of cases, we examine the strongly recurving nonoutbreak hurricanes over the eastern United States. Seven cases were chosen from Table 2 and their 500-hPa geopotential height fields were composited (Fig. 8). These results show that a 500-hPa trough lies to the northwest of the hurricane at landfall (Fig. 8a, c), which, by a day after landfall, has moved eastward (Fig. 8b, d). These results are reminiscent of the northwest composite of extratropical transition over the western North Pacific noted by Harr et al (2000). Furthermore, the results of Fig. 8 support those of the synoptic composites from the Texas storms in Fig. 7 that hurricane interaction with the jet stream results in recurvature. Whereas this interaction and recurvature may lead to tornado outbreaks in the Texas cases, the right-front quadrant tends to be offshore in the east-coast recurvature cases, so tornadoes are not likely to be observed over land, if they are even produced at all.

To summarize, simple statistical tests on the location of landfall only provide part of the ex- planation for whether an outbreak occurs. When the statistical methodology is combined with synoptic composites, physical insight is obtained. Despite the relative success of these composites on the synoptic scale, mesoscale and storm-scale effects may produce an environment favorable for tornadoes or a tornado outbreak in an atypical synoptic-scale environment, as might have been the case with Beulah's unusual track.

Before leaving this discussion, this paper is not the first attempt to relate the track of landfalling hurricanes to tornadogenesis. Novlan and Gray (1975) plotted landfall location and tracks for hurricanes that produced tornadoes vs those that did not. They did not see as clean a distinction as we did. This apparent discrepancy suggests that our approach of distinguishing outbreak from nonoutbreak is more successful than attempting to distinguish tornado from no-tornado.

\subsection{Hurricane origin and date of landfall}

Three areas of the North Atlantic Basin were identified as hurricane origin sites. First, the Atlantic Ocean was defined as the area north and east a diagonal line from Key West, FL, southeastward towards Cuba, Haiti, and the Dominican Republic ending near Trinidad and Tobago. Next, the Caribbean Sea was defined as the area south and west of the same diagonal line and south of $\sim 23^{\circ} \mathrm{N}$ latitude near the Yucatan Peninsula. Last, the Gulf of Mexico was identified as the area north and west of the Yucatan

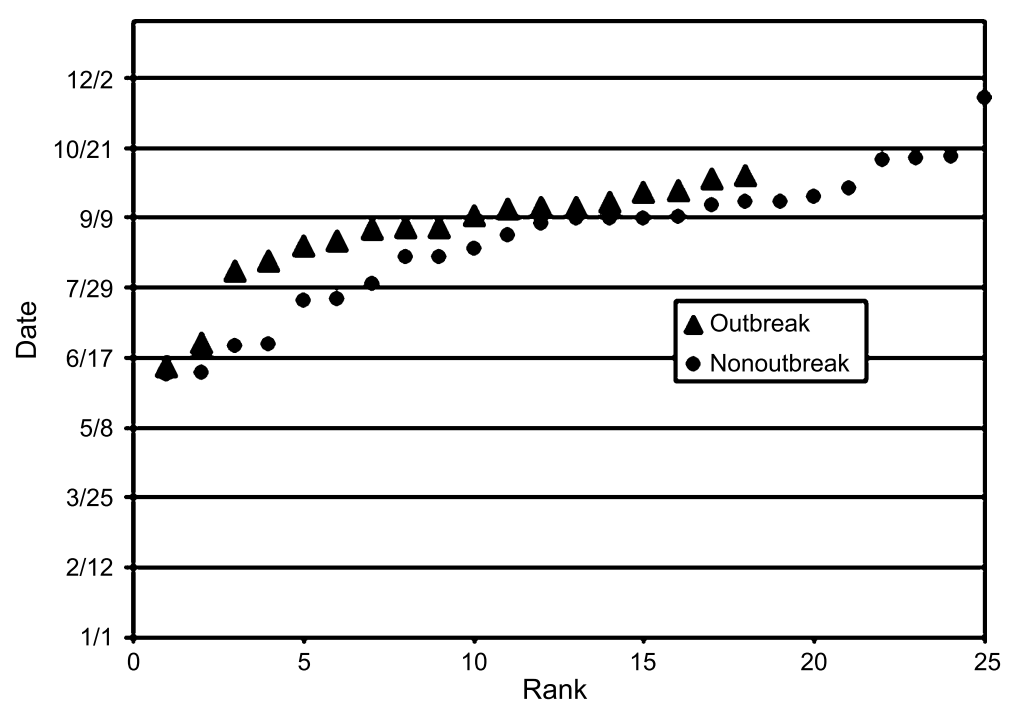

Fig. 9. Ranked distribution of outbreak (triangles) and nonoutbreak (circles) hurricanes by date from 1954 to 2004 
Peninsula and Cuba and waters west of Key West, FL. The Atlantic Ocean is the largest and most active body of water and produced 38 United States hurricane landfalls from 19542004. Furthermore, the Caribbean Sea and Gulf of Mexico formed 34 hurricane landfalls that affected the United States. Hurricane origin was investigated as a possible parameter that may distinguish between outbreak and nonoutbreak hurricanes, yet no significant relationship was found.

Additionally, date of landfall was inspected in order to determine if outbreak and nonoutbreak hurricanes favor a certain time of year. To distinguish between outbreak hurricanes and nonoutbreak hurricanes, Fig. 9 shows the ranked distribution of landfall date for each classification. There appears to be a small gap in outbreak hurricanes between June and August (Fig. 9), consistent with Hagemeyer (1997) who showed that the months of July and August had a relative deficiency in tornado reports for Florida peninsular outbreaks. One possible explanation for this shortage was noted by Hagemeyer and Schmocker (1991). They found that, in the middle of the wet season (July and August in Florida), tornado environments were characterized by weak lowertropospheric winds and very low shear; consequently contributing to the lack of tornadogenesis in the region. Even though date of landfall was not found to be a statistically significant parameter in distinguishing between outbreak and nonoutbreak hurricanes, it is interesting to note the general lack of outbreak cases in July.

\subsection{El Niño-Southern Oscillation (ENSO) phase}

There have been many studies on the effect of ENSO on hurricanes in the North Atlantic basin (e.g., Gray, 1984; Bove et al, 1998; Pielke and Landsea, 1999; Larson et al, 2005). These studies show that El Niño events suppress hurricane and tropical storm activity because of the abnormally strong upper-tropospheric westerlies in the western Atlantic and Caribbean. La Niña events, on the other hand, increase the number of hurricanes and tropical storms in the Atlantic basin, increase the frequency of damaging landfalling storms, and increase the amount of damage per storm. Hagemeyer (1999) found the relationship between ENSO and hurricane-spawned tornadoes in Florida to be unclear. To attempt to resolve some of these discrepancies, we examined the effect of ENSO on tornado outbreaks associated with hurricanes with our dataset.

Rasmusson and Carpenter (1982) demonstrated that sea-surface temperature (SST) anomalies can identify the onset of an El Niño event in late spring to early summer, and the peak in SST anomalies occur in December, January, and February (i.e., Northern Hemisphere winter). To determine the phase of ENSO during the months of peak hurricane activity (August, September, and October), we used the Climate Prediction Center's Oceanic Niño Index (ONI) for Niño 3.4 SST anomalies based on the 1971-2000 period (http://www.cpc.ncep.noaa.gov/products/ analysis_monitoring/ensostuff/ensoyears.shtml). The ONI indicates an El Niño event when the

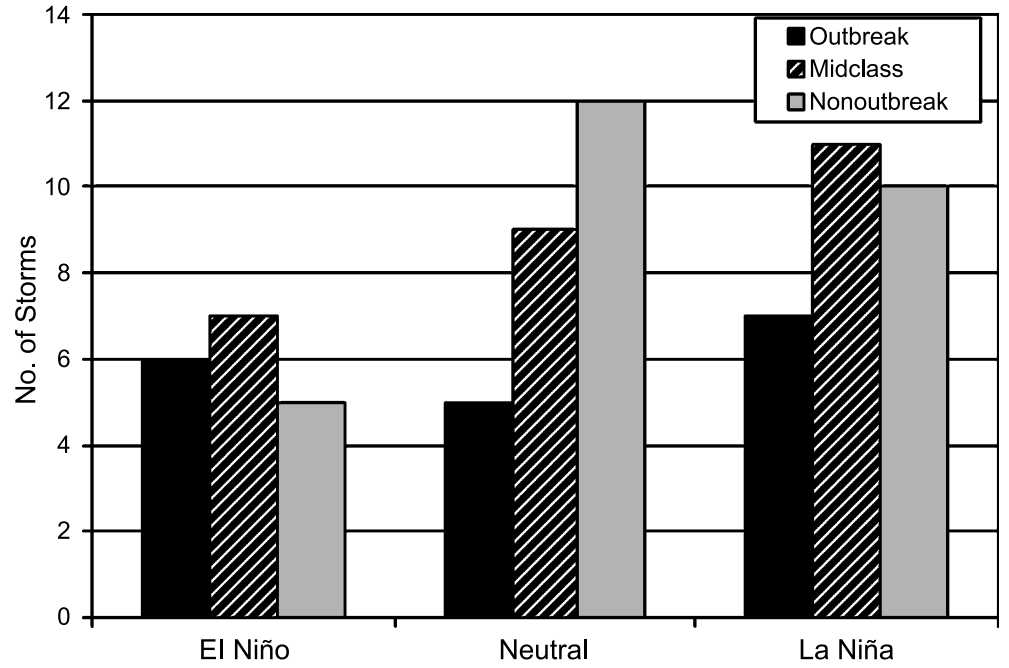

Fig. 10. Number of outbreak (black), midclass (gray hatched), and nonoutbreak (gray) hurricanes by ENSO phase. ENSO phase was determined by the Climate Prediction Center's Niño 3.4 sea-surface temperature anomalies for August, September, and October 
Niño 3.4 SST anomaly is greater than or equal to $0.5^{\circ} \mathrm{C}$, and a La Niña event when the anomaly is less than or equal to $-0.5^{\circ} \mathrm{C}$. Anomalies between $-0.5^{\circ} \mathrm{C}$ and $0.5^{\circ} \mathrm{C}$ are considered neutral years. Figure 10 illustrates each hurricane classification and the respective El Niño, neutral, or La Niña phase during August, September, and October of the hurricane year. More hurricanes occurred during non El Niño years (26 in neutral phases; 28 in La Niña phases) than in El Niño years (18), in agreement with previous studies (e.g., Gray, 1984; Bove et al, 1998; Pielke and Landsea, 1999; Larson et al, 2005). Six outbreak hurricanes occurred during El Niño events and seven occurred during La Niña events. Therefore, if a landfalling hurricane occurred during an El Niño year, the event had a higher chance of being associated with a tornado outbreak (6 outbreaks of 18 , or $33 \%$ ), as opposed to if the hurricane occurred during non El Niño (neutral or La Niña) years (12 outbreaks of 54, or 22\%). However, a statistically significant relationship was not found between outbreak and nonoutbreak hurricanes and El Niño vs non-El Niño years using a chi-square test and one degree of freedom ( $p$ value $=0.26$ ). A much longer period of observations will be required to assess whether this relationship is significant or just due to random variations and the small sample size.

\section{Summary and conclusions}

This study examined all landfalling hurricanes that affected the United States from 1954 to 2004. Criteria developed by Verbout et al (2005) was used to examine days with a large number of tornadoes across the United States (big tornado days) and later to develop a dataset of tornado outbreaks associated with hurricanes and nonoutbreak hurricanes. The results of the present study, as well as a review of the previous literature, indicates the following characteristics are capable of distinguishing landfalling hurricanes that produce tornado outbreaks from those that do not.

More intense hurricanes are more likely to produce tornadoes (Novlan and Gray, 1974; Gentry, 1983; McCaul, 1991; this study). Hurricanes that are weakening are more likely to produce tornadoes (Hill et al, 1966; Novlan and Gray, 1974), although this effect may be more likely due to the fact that most hurricanes are weakening as they approach land.

Previous studies have argued that hurricanes recurving to the northeast were more likely to produce tornadoes than those moving westward (Smith, 1965; Hill et al, 1966; Novlan and Gray, 1974). By exception, one of the most prolific tornado-producing storms, hurricane Beulah (1967), did not behave in this manner (Fig. 1). Although there is some skepticism about the validity of this rule (Novlan and Gray, 1974), nearly all our outbreak cases (Fig. 6a) exhibited recurvature over the southern or eastern United States. By contrast, nearly all our nonoutbreak cases (Fig. 6b) did not recurve or recurved along or off the eastern United States. Composite synoptic analyses for landfalling hurricanes that affected Texas show that distinct synoptic patterns distinguish outbreaks from nonoutbreaks due to the location of the jet stream. Outbreaks were associated with a 500-hPa trough over the northcentral United States, allowing the jet stream to dip equatorward over the central United States (Fig. 7a). With such a synoptic pattern, landfalling hurricanes that affected Texas experienced recurvature quickly (Fig. 6a). Nonoutbreaks, on the other hand, were associated with a $500-\mathrm{hPa}$ ridge over the north-central United States and a jet stream in southern Canada (Fig. 7b). As such, recurvature was less likely, and the tracks of Texas nonoutbreak hurricanes showed a westward or northwestward track once onshore (Fig. 6b).

Hurricanes that recurve along or off the eastern United States do not produce tornado outbreaks because their right-front quadrant is not over the land for an extended period of time (Hill et al, 1966; Novlan and Gray, 1974; McCaul, 1991; this study). Most tornadoes are found in the right-front quadrant relative to the motion of the hurricane (Malkin and Galway, 1953; Pearson and Sadowski, 1965; Smith, 1965; Orton, 1970; Novlan and Gray, 1974; Gentry, 1983; McCaul, 1991). This quadrant is where the greatest deep-layer shear and helicity are found (McCaul, 1991; Bogner et al, 2000), typical ingredients for mesocyclogenesis and tornadogenesis, respectively. Air parcels in the right-front quadrant also have a recent history of being over water, and the right-front quadrant is where convection tends to be strongest (e.g., Gentry, 1983). Outbreak hurricanes have stronger low-level 
wind shear than nonoutbreak hurricanes (Wills, 1969; Novlan and Gray, 1974; McCaul, 1991; this study). This result is consistent with the requirement for strong low-level wind shear for tornadogenesis.

Gray (1984), Bove et al (1998), Pielke and Landsea (1999), Larson et al (2005) and this study have shown that Atlantic basin hurricanes tend to occur during non El Niño years. The number of outbreak hurricanes, however, was nearly evenly split between El Niño and La Niña years. This study also found the following characteristics were not useful for distinguishing outbreaks from nonoutbreaks: storm origin and date of landfall.

The results of this study allow forecasters to identify the factors that affect tornado outbreaks with landfalling hurricanes, with the goal of being better able to anticipate these events. As our results show, the statistics suggest better discrimination between outbreak and nonoutbreak hurricanes rather than the occurrence of tornadoes or no tornadoes. This effect may explain some contradictory results in the previous literature.

\section{Acknowledgments}

We thank Dan McCarthy and NOAA/NWS/Storm Prediction Center for providing the tornado data and the NOAA/ NWS/Tropical Prediction Center for providing the hurricane data. Thanks to Brad Barrett for his assistance with the hurricane data. Schultz thanks Paul Hoffmann (MIT) for his early collaboration on this topic. This manuscript benefited from the comments from Richard Thompson and several anonymous reviewers. Verbout was funded by a research assistantship through U.S. Office of Naval Research grant N00014-0021-1-0181. Funding for Schultz was provided by NOAA/OAR/NSSL under NOAA-OU Cooperative Agreement NA17RJ1227.

\section{References}

Bogner PB, Barnes GM, Franklin JL (2000) Conditional instability and shear for six hurricanes over the Atlantic Ocean. Wea Forecast 15: 192-207

Bove MC, Elsner JB, Landsea CW, Niu X, O’Brien JJ (1998) Effect of El Niño on U.S. landfalling hurricanes, revisited. Bull Amer Meteor Soc 79: 2477-2482

Brooks HE, Doswell CA III, Kay MP (2003) Climatological estimates of local daily tornado probability for the United States. Wea Forecast 18: 626-640

Curtis L (2004) Midlevel dry intrusions as a factor in tornado outbreaks associated with landfalling tropical cyclones from the Atlantic and Gulf of Mexico. Wea Forecast 19: $411-427$
Doswell CA III, Burgess DW (1988) On some issues of United States tornado climatology. Mon Wea Rev 116: 495-501

Efron B, Tibshirani RJ (1993) An introduction to the bootstrap. Chapman and Hall, $436 \mathrm{pp}$

Elmore KL, Stensrud DJ, Crawford KC (2002) Ensemble cloud model applications to forecasting thunderstorms. J Appl Meteor 41: 363-383

Elmore KL, Baldwin ME, Schultz DM (2005) Field significance revisited: spatial bias errors in forecasts as applied to the Eta model. Mon Wea Rev 134: 519-531

Franklin JL, McAdie CJ, Lawrence MB (2003) Trends in track forecasting for tropical cyclones threatening the United States, 1970-2001. Bull Amer Meteor Soc 84: 1197-1203

Galway JG (1975) Relationship of tornado deaths to severe weather watch areas. Mon Wea Rev 103: 737-741

Galway JG (1977) Some climatological aspects of tornado outbreaks. Mon Wea Rev 105: 477-484

Gentry RC (1983) Genesis of tornadoes associated with hurricanes. Mon Wea Rev 111: 1793-1805

Gray RW (1919) A tornado within a hurricane area. Mon Wea Rev 47: 639-639

Gray WM (1984) Atlantic seasonal hurricane frequency, Part I: El Niño and $30 \mathrm{mb}$ quasibiennial oscillation influences. Mon Wea Rev 115: 1649-1668

Grazulis TP (1993) Significant tornadoes, 1680-1991. Environmental Films, 1326 pp

Hagemeyer BC (1997) Peninsular Florida tornado outbreaks. Wea Forecast 12: 399-427

Hagemeyer BC (1998) Significant tornado events associated with tropical and hybrid cyclones in Florida. Preprints 16th Conf. on Weather Analysis and Forecasting Phoenix, AZ, Amer Meteor Soc, pp 4-6

Hagemeyer BC (1999) El Niño and significant tropical and hybrid cyclone tornado events in Florida. Preprints 23rd Conf. on Hurricanes and Tropical Meteorology, Dallas, TX, Amer Meteor Soc, pp 415-418

Hagemeyer BC, Hodanish SJ (1995) Florida tornado outbreaks associated with tropical cyclones. Preprints $21 \mathrm{st}$ Conf. on Hurricanes and Tropical Meteorology, Miami, FL, Amer Meteor Soc, pp 312-314

Hagemeyer BC, Schmocker GK (1991) Characteristics of east central Florida tornado environments. Wea Forecast 6: 499-514

Hagemeyer BC, Spratt SM (2002) Thirty years after hurricane Agnes - The forgotten Florida tornado disaster. Preprints 25th Conf. on Hurricanes and Tropical Meteorology, San Diego, CA, Amer Meteor Soc, pp 422-423

Harr PA, Elsberry RL, Hogan TF (2000) Extratropical transition of tropical cyclones over the western North Pacific. Part II: The impact of midlatitude circulation characteristics. Mon Wea Rev 128: 2634-2653

Hill EL, Malkin W, Schulz WA Jr (1966) Tornadoes associated with cyclones of tropical origin-practical features. J Appl Meteor 5: 745-763

Hills GB (1929) The September 28, 1929, tornado in Fort Lauderdale, FL. Mon Wea Rev 57: 420-421

Hoadley DK (1981) A tropical storm David tornado in Fairfax County - September 1979. Bull Amer Meteor Soc 62: 498-507 
Jones SC, coauthors (2003) The extratropical transition of tropical cyclones: Forecast challenges, current understanding, and future directions. Wea Forecast 18: 1052-1092

Kalnay E, coauthors (1996) The NCEP/NCAR 40-Year Reanalysis project. Bull Amer Meteor Soc 77: 437-471

Landsea CW, coauthors (2004) A reanalysis of hurricane Andrew's intensity. Bull Amer Meteor Soc 85: 1699-1712

Larson J, Zhou Y, Higgins RW (2005) Characteristics of landfalling tropical cyclones in the United States and Mexico: Climatology and interannual variability. J Climate 18: 1247-1262

Livezey RE, Chen WY (1983) Statistical field significance and its determination by Monte Carlo techniques. Mon Wea Rev 111: 46-59

Malkin W, Galway JG (1953) Tornadoes associated with hurricanes as illustrated by Franconia, VA, tornado, September 1, 1952. Mon Wea Rev 81: 299-303

McCarthy DW (2003) NWS tornado surveys and the impact on the national tornado database. Preprints 1st Symp. on F-scale and Severe Weather Damage Assessment, Long Beach, CA, Amer Meteor Soc (CD-ROM: 3.2)

McCaul EW Jr (1987) Observations of the hurricane "Danny" tornado outbreak of 16 August 1985. Mon Wea Rev 115: 1206-1223

McCaul EW Jr (1991) Buoyancy and shear characteristics of hurricane-tornado environments. Mon Wea Rev 119: 1954-1978

McCaul EW Jr, Weisman ML (1996) Simulations of shallow supercell storms in landfalling hurricane environments. Mon Wea Rev 124: 408-429

McCaul EW Jr, Buechler DE, Goodman SJ, Cammarata M (2004) Doppler radar and lightning network observations of a severe outbreak of tropical cyclone tornadoes. Mon Wea Rev 132: 1747-1763

Neumann CJ, Jarvinen BR, McAdie CJ, Hammer GR (1999) Tropical cyclones of the North Atlantic Ocean, 18711998. Historical Climatology Series 6-2. National Climatic Data Center Asheville, NC in cooperation with the Tropical Prediction Center/National Hurricane Center Miami, FL, 206 pp

Novlan DJ, Gray WM (1974) Hurricane-spawned tornadoes. Mon Wea Rev 102: 476-488

Novlan DJ, Gray WM (1975) Reply. Mon Wea Rev 103: $1021-1023$

Orton R (1970) Tornadoes associated with hurricane Beulah on September 19-23, 1967. Mon Wea Rev 98: 541-547

Pearson A (1975) Comments on "Hurricane-spawned tornadoes." Mon Wea Rev 103: 1021

Pearson A, Sadowski AF (1965) Hurricane-induced tornadoes and their distribution. Mon Wea Rev 93: 461-464
Pielke RA Jr, Landsea CW (1999) La Niña, El Niño, and Atlantic hurricane damages in the United States. Bull Amer Meteor Soc 80: 2027-2033

Pielke RA Jr, Pielke RA Sr (1997) Hurricanes: their nature and impacts on society. Wiley, $279 \mathrm{pp}$

Rasmusson EM, Carpenter TH (1982) Variations in tropical sea surface temperature and surface wind fields associated with the Southern Oscillation/El Niño. Mon Wea Rev 110: $354-384$

Rudd MI (1964) Tornadoes during hurricane Carla at Galveston. Mon Wea Rev 92: 251-254

Sadowski AF (1962) Tornadoes associated with hurricane Carla, 1961. Mon Wea Rev 90: 514-516

Smith JS (1965) The hurricane-tornado. Mon Wea Rev 93: 453-459

Spratt SM, Sharp DW, Welsh P, Sandrik A, Alsheimer F, Paxton C (1997) A WSR-88D assessment of tropical cyclone outer rainband tornadoes. Wea Forecast 12: 479-501

Stiegler DJ, Fujita TT (1982) A detailed analysis of the San Marcos, Texas tornado induced by hurricane "Allen" on 10 August, 1980. Preprints 12th Conf. on Severe Local Storms. Amer Meteor Soc, pp 371-374

Tannehill IR (1938) Hurricanes: their nature and history. Princeton University Press, $257 \mathrm{pp}$

Verbout SM, Brooks HE, Leslie LM, Schultz DM (2005) Evolution of the United States tornado database: 19542003. Wea Forecast 21: 86-93

Wang X, Shen SS (1999) Estimation of spatial degrees of freedom of a climate field. J Climate 12: 1280-1291

Watson AI, Jamski MA, Turnage TJ, Bowen JR, Kelley JC (2005) The tornado outbreak across the north Florida panhandle in association with hurricane Ivan. Preprints 32nd Radar Conf. Amer Meteor Soc (CD-ROM: 10R.3)

Weiss SJ (1985) On the operational forecasting of tornadoes associated with tropical cyclones. Preprints 14th Conf. on Severe Local Storms, Indianapolis, IN, Amer Meteor Soc, pp 293-296

Weiss SJ (1987) Some climatological aspects of forecasting tornadoes associated with tropical cyclones. Preprints 17th Conf. on Hurricanes and Tropical Meteorology, Miami, FL, Amer Meteor Soc, pp 160-163

Wilks DS (1995) Statistical methods in the atmospheric sciences. Academic Press, 467 pp

Wills TG (1969) Characteristics of the tornado environment as deduced from proximity soundings. Preprints 6th Conf. on Severe Local Storms, Chicago, IL, Amer Meteor Soc, pp 222-229

Corresponding author's address: Stephanie M. Verbout, School of Meteorology/National Weather Center, University of Oklahoma, 120 David L. Boren Blvd, Norman, OK 73072, USA (E-mail: stephanieverbout@hotmail.com) 